\title{
Movement of knowledge \\ Introducing medical humanities perspectives on medicine, science, and experience
}

\author{
Kristofer Hansson \& Rachel Irwin
}

Medical knowledge is always in motion. It moves from the lab to the office, from a press release to a patient, from an academic journal to a civil servant's desk and then on to a policymaker. Knowledge is deconstructed, reconstructed, and transformed as it moves. The dynamic, ever-evolving nature of medical knowledge has given rise to different concepts to explain it: diffusion, translation, circulation, transit, co-production. At the same time, its movements-and the ways in which we conceptualize and describe them-have material consequences. For instance, value judgements on the validity of certain forms of knowledge determine the direction of clinical research. Policy decisions are taken in relation to existing knowledge. The acceptance or rejection of treatment protocols based on medical 'facts' impacts patients, dependents, health providers, and society at large. Simply put, knowledge and the movement of knowledge matter.

How do they matter, though? The contributors to this volume examine the complexity of medical knowledge in everyday life. We demonstrate not only the pervasive influence of knowledge in medical and public health settings, but also the range of methodological and theoretical tools to study knowledge. Ours is a multidisciplinary approach to the medical humanities, presenting both contemporary 
and historical perspectives in order to explore the borderlands between expertise and common knowledge. The medical humanities have a long history of addressing questions of context, experience, and representation in medical and public health settings (Cole et al. 2015), and thus have an enduring interest in the relationships, and expectations of these relationships, among the various actors who have a part in the motion of knowledge, whether medical specialists, policymakers, or, of course, patients and their carers.

Many of the chapters have an empirical basis in southern Sweden. The research has been carried out in close collaboration with medical researchers, practitioners, and patients, and thus reflects a specific form of healthcare setting which is strongly influenced not only by the 'traditional' Swedish welfare model, but also by the neoliberalization of this model in recent decades (see also Nordgren \& Hansson 2019). In this way, our research can be framed as something that Peter Keating and Alberto Cambrosio (2006) define as a biomedical platform, or a set of activities where biomedical research, meetings between professionals and patients, the communication of medical information, and so forth take place. Such a platform 'is more than an instrument or device, but is a specific configuration of instruments and individuals that share common routines and activities, held together by standard reagents' (23). One of our themes is how medical knowledge is part of common routines and activities, and we also consider how these kinds of platforms influence and are influenced by the configurations of globalization and neoliberalization. The discourses and practices of clinical trials, diagnostics, and policymaking take similar forms wherever one is in the global scientific community, yet at the same time we see how these processes are situated in specific local contexts. In this way, the volume contributes not only to the development of medical humanities perspectives in Sweden, but is also relevant to international scholars.

Each of the chapters highlights the need to reflect on the movement of knowledge and to create a bridge between different disciplines, thus widening the opportunities for the humanities and 
sciences to collaborate. Medical knowledge influences everyday life, both in medical settings and beyond. We argue that an interdisciplinary approach will not only improve the handling of clinical encounters, but will also improve everyday life outside the clinic (Mol 2008). In this introduction we look at how medical knowledge can be addressed in the medical humanities vis-à-vis the main empirical themes of the volume. The wide range of approaches is a reflection of the multifaceted nature of the concepts used to describe the movement of knowledge. This is further evident as we present the chapters, which provide a breadth of perspectives on medical knowledge, illuminating different aspects of the journey and offering ways forward.

\section{Conceptualizing knowledge}

The medical humanities have a role in the continuously evolving world of biomedicine, for mediating and scrutinizing the new and unstable knowledge produced in different arenas. In this volume, we borrow the concept of multistability from the post-phenomenologist and philosopher of science Don Ihde (2012), which, when applied to knowledge, acknowledges that it is used by different actors for different purposes, and that it has different and multiple meanings in different periods and contexts. This becomes apparent in the study of medical knowledge in contemporary healthcare and biomedicine.

At the same time, the concept of multistability must be contextualized, for there is a long research tradition in both the humanities and the social sciences of focusing on questions concerning the nature and production of knowledge (Pickstone 2000). For instance, society entered a post-industrial era in the 1950 os and 1960s, characterized by growing health and education sectors-and a transformation of how knowledge was valued and handled (Drucker 1969; Bell 1973). This is explored in Anna Tunlid's chapter on how prenatal diagnosis changed not only the production of knowledge in medical research, but also public debate: new medical knowledge from the 
rapidly expanding biomedical research field resulted in new views on the prenatal body.

In the late 1970 and 1980 os postmodernism came to dominate all kinds of solid knowledge, instead arguing that there were no longer any knowledge values that were superior to others (Lyotard 1979). The postmodern theory of knowledge posited by social constructionism also provides a starting point for critiquing the relationship between knowledge and power. In the humanities this perspective has had a significant influence on both research methods and theories, not least in the medical humanities. In fact, this change has been fundamental to the medical humanities as a field, and all the chapters in this volume relate to social constructionism to some degree.

This intimate relationship between knowledge and power is also found in the work of Michel Foucault (1980), one of the most influential researchers in the field of medical humanities. For instance, the chapters in this volume address how knowledge is controlled and used to control, while at the same time influencing power structures-that is, knowledge bases are used to justify courses of action (Gutting 2005). This is writ large in healthcare settings, where a body of evidence can promote certain policies over others. Kristofer Hansson's chapter, for example, focuses on how technology and medical knowledge in diabetes care are used to justify certain actions, and how technology and knowledge mediate relationships between the families of children who have been diagnosed with diabetes and health professionals.

Others have focused on authoritative knowledge. What counts or does not count as knowledge is a long-standing concern in the social sciences, science and technology studies (STS), anthropology, and sociology. Many scholars have critiqued biomedicine as an unquestioned and now dominant cultural system (see Latour \& Woolgar 1979; Mishler 1981; Starr 1982; Jordan 1983; Hahn \& Gaines 1985). Using Sheila Jasanoff's term 'co-production' (2004) we would argue that knowledge is not only socially and culturally produced, but that it also generates the sociocultural context in which researchers are situated. Jasanoff defines scientific knowledge 
as something that 'both embeds and is embedded in social practices, identities, norms, conventions, discourses, instruments and institutions' $(2004,3)$. Several of the chapters in this volume expand upon Jasanoff's co-production concept, and similarly we argue that there is a need for a focus on the myriad connections between all the actors in the biomedical platform. The individual chapters provide examples of this co-production, but it is when we take a view of the whole platform that a broader analysis is possible. We cannot separate knowledge from the lifeworld in which we live (Husserl 1972), which means that knowledge is closely linked to and depends on power and culture, science, medicine, and society. The philosopher Ian Hacking (1996) discusses looping effects: how knowledge not only gives us new perspectives on life, but also changes actual life practices. In medicine, new categorizationsfor example, a new way of measuring or defining disease-also means that we as researchers, medical professionals, and patients act in new ways. The anthropologists Margaret Lock and Mark Nichter (2002) pursue this idea by drawing on Foucauldian motifs to describe the export of biomedicine as a form of governmentality and neo-colonialism. They write that the processes of modernization and Westernization have imposed norms for 'what counts as evidence, legitimacy in policymaking, privileged knowledge, definition of disease categories' $(3-4,10)$, which in turn causes tensions 'between traditional values that define identity and the forces of modernization and globalization' (8) and fuels a debate about the dominance of a specific paradigm, evidence-based medicine.

\section{Knowledge and evidence-based medicine}

It is through the lenses of power, knowledge, and authority that specific developments in evidence-based medicine have been described. We use evidence-based medicine as an umbrella term to describe developments-over roughly the past thirty years-in how knowledge is validated, and the use of 'robust' testing to produce knowledge. Evidence-based medicine is often defined as 'the process 
of systematically finding, appraising, and using contemporaneous research findings as the basis for clinical decisions' (Roberts \& Yeager 2006, 68; see also Rosenberg \& Donald 1995), and we analyse it from a variety of theoretical and empirical perspectives. Originating from medical science, evidence-based medicine is considered first-rate knowledge with ostensibly objective verifications of reality, and as such is the kind of methodologically robust knowledge that medical professionals and biomedical researchers value. At the same time, this knowledge, when it is circulated and shared, is juxtaposed with practical relevance (Bohlin \& Sager 2011), as discussed in Rachel Irwin's chapter here. Medical knowledge does not always reflect the lived experience of health professionals, patients, and carers.

The push for evidence-based medicine in healthcare from the turn of the twenty-first century has radically changed the medical care offered to patients, as well as changing the work environment in hospitals and laboratories (see also Bohlin \& Sager 2011; Berner \& Kruse 2013). This same perspective on knowledge is finding its way out from healthcare, something that is addressed in Karolina Lindh's chapter on the role of press releases about the latest science discoveries in how knowledge produced in laboratories reaches the public.

A closely connected development is the ongoing digitalization of life, which is transforming how we relate to and process evidence-based knowledge. New digital tools are an important part of the development of contemporary biomedical research and medical practice (Beaulieu 2004; Dumit 2004; Carusi \& Hoel 2014). Digital patient registers, digital monitoring, digital diagnostic tools, and other technologies change the ways nurses and doctors work, and, in a broader sense, healthcare has been reorganized to accommodate evidence-based medicine about the patient and the patient's body. It is crucial in both hospitals and laboratories 'that we can talk about a new form of medicine-informatics medicine-with its own practices of knowledge and development' (Eklöf \& Normark $2018,345)$. At the same time, this informatics medicine offers important social arenas and global markets in which patients and 
others can discover new knowledge and treatments that are not offered by their local healthcare systems.

From a medical humanities perspective, we see major advantages in revisiting classic studies to gain new perspectives on the latest developments in medicine. The study of evidence-based medicine with the concept of authoritative knowledge was developed by the medical anthropologist Brigitte Jordan in her study, Birth in Four Cultures from 1978 (1993), in which she demonstrates how technology created a 'regime of power' in the birth process by generating authoritative knowledge and delegitimizing indigenous knowledge about the birth process. Authoritative knowledge is 'the knowledge that is constructed and displayed by members of a community of practice as the basis for legitimate decision-making' (xiii). In any given domain, parallel knowledge systems exist, but one often gains primacy (150-1). Authoritative knowledge emerges as the 'natural' way of things, even though it is a cultural system that is consciously and unconsciously reproduced. In this framework, some kinds of knowledge count and others do not, regardless of 'truth value' (149). In the example of birth and reproduction, Jordan finds that doctors often rely on technology (such as foetal heart monitors) rather than the mother's experience or the experience of (non-professional) midwives. In a contemporary perspective, evidence-based medicine can be said to be a form of authoritative knowledge, as discussed here in Rui Liu and Susanne Lundin's chapter on the grey market in medicines and how different knowledge regimes challenge one another. We would argue that a key methodological perspective in the medical humanities is to understand evidence-based medicine relative to what can be called everyday experience.

\section{Knowledge in everyday experience}

Everyday experience provides a starting point when questioning traditional doctor-patient relationships or patients' and carers' lived experiences, both of which are crucial to understanding the movement of knowledge and whose knowledge 'counts' (Frykman \& 
Gilje 2003; Normark 2019). The span is wide. They can be patients with Parkinson's disease understanding informed consent in a medical trial, as in Markus Idvall's chapter; they can be parents whose children have recently been diagnosed with diabetes and are trying to understand care practices, as in Hansson's chapter. In terms of phenomenology, a focus on the knowledge created from everyday experience provides insight into what it means to be human in varying medical practices (Becker 1992; King et al. 2017). In this vein, the philosopher Julia Kristeva and her colleagues have invited us to rethink the medical humanities:

A new programme for the medical humanities should involve a radical concern with cultural dimensions of health as more than a subjective dimension outside the realm of medical science. We will explore the notion that all clinical encounters should be considered as cultural encounters in the sense that they involve translation between health as a biomedical phenomenon and healing as lived experience. Hence, our assumption is that the cultural crossings of care are not an exception but the norm. Given this, every clinical encounter should involve a simultaneous interrogation of the patient's and the doctor's co-construction of new and shared meanings that can create realities with medical consequences, not 'mere' symbols of 'real' medical issues. (Kristeva et al. 2018, 57)

Much of the focus of the present volume is the public reconstruction of knowledge from medicine and science (Rose 2007; Gottweis 2008; Hansson 2017). It can be a person sitting at a computer trying to understand online knowledge; a patient meeting a doctor or nurse; a member of the public reading a press release about a new medicine; a person sitting in front of a piece of art as in Max Liljefors's chapter. It is from such a perspective that some of the multistability of knowledge can be understood. Taking a more philosophic perspective, it becomes clear that the question is centuries old. Ludwig Wittgenstein's admission 'I don't merely have the visual impression of a tree: I know that it is a tree' (On Certainty, 
$\$ 267$ ) is central, but when do we know? In this volume we are not interested in what can be defined as truth and knowledge per se; instead, our methods are designed to gauge the lifeworlds of those who interpret the knowledge that surrounds them.

Borrowing from the historian James A. Secord (2004), we discuss knowledge in transit. Secord's proposed change in perspective on knowledge has been central for humanities research in recent years (Östling et al. 2020), and we find the move away from knowledge as a communicative action to knowledge as a form of doing of science to be a fruitful one. Specifically, Secord writes that 'we need to shift our focus and think about knowledge-making itself as a form of communicative action' (2004: 661), and in discussing knowledge in transit he argues that knowledge should always be seen as a form of communication. Indeed, the communicative aspects of knowledge are increasingly central considerations in medicine, healthcare, and public health.

We offer examples of the communicative aspect to science transmission between researchers, between researchers and the public, and between civil servants and policymakers. Such practices are central not only to any understanding of how science and medicine produce knowledge, but also to how knowledge production is a form of knowledge in action (see Schütz \& Parsons 1978). For instance, as medical knowledge circulates it is also enacted. This enactment consists of what people do with 'information artefacts'-how press releases, articles, and books are not only embedded in a context, but also are used in different ways (Buckland 2012), as examined in Åsa Alftberg's and Lindh's chapters. For the medical humanities, a central question is therefore how knowledge from biomedicine and healthcare is set in motion in the everyday lives of patients or relatives (Kleinman 1988).

The relationship 'between health as a biomedical phenomenon and healing as lived experience' (Kristeva et al. 2018, 57) is not unproblematic. Modern medicine has long viewed biomedical phenomena as 'largely free from values, meaning and desire, as opposed to the afflicted laypeople's views' (Wiszmeg 2017, 74). This 
begs the question of which actors have the best arguments: Is it the researchers or the public? Is it the medical doctors or the patients (Wynne 1996; Pellizzoni 2001)? Recent years have seen a change, as the contradictions between science and alternative facts, especially in the social media, are exposed, which is considered here in Liu and Lundin's chapter about falsified medicines. Digitalization has led to the spread of knowledge and is a platform for creating and resolving differences of opinion. For example, we find communities of so-called fact resisters who are seemingly impervious to facts that contradict their own perception. This has given rise to movements that rally to the defence of medical knowledge and its significance for a modern, progressive society (see Frans 2017), which may involve practitioners where, for example, advocates of alternative approaches argue that vaccination programmes are risky, invoking alternative information in social media. Communication is also often discussed in relation to the questioning of evidence-based medicine by, for example, the anti-vaccination movement.

While it is important to defend medical knowledge, in the humanities we are interested in understanding the various actors' perspectives rather than criticizing them (see also Haraway 1985; Latour 2003; Rose 2013; Hansson \& Lindh 2018; see also Hansson, Nilsson \& Tiberg in this volume). While fact resistance and online discussions may lead to illegalities - such as purchasing counterfeit medicines online as Liu and Lundin describe in this volume-they also highlight what is missing in society. As Lindh asks in her chapter, what happens when evidence and popular understanding, politics and ideology, conflict? From a medical humanities perspective, we argue that studying differences of opinion or the lack of trust in biomedicine offers key insights into the ways in which medical knowledge moves.

\section{Presentation of the chapters}

The volume falls into four sections, each addressing a specific issue of how medical knowledge relates to biomedical platforms. It begins with a section-'Medical knowledge and the political' - that 
focuses on the biomedical platform as part of a sociopolitical context, investigating relations between communities and healthcare systems, and with medical knowledge seen as something that moves between them, affecting political decisions which, in turn, affect the healthcare system. The next section-'Circulating and sharing medical knowledge' - focuses on how medical knowledge circulates in biomedical platforms and how researchers share knowledge with other researchers or the public. The third section-'Co-creation of medical knowledge'-focuses on the ethical tools and co-creation of evidence-based medicine as a way to bridge between the posited circulation of 'objectified' knowledge and therapeutic knowledge. Finally, section four-'Knowledge in everyday experience'develops therapeutic knowledge and its interface with patient and patient families with a focus on self-knowledge.

The first section starts with Anna Tunlid's chapter, 'Prenatal diagnosis: Co-production of knowledge and values in medical research and public debate', a discussion of how social, political, and ethical factors formed an integral part of foetal diagnostics when they were developed and used in a clinical context in the 1960s and 1970s, as well as how these factors affected the public debate about foetal diagnosis in the early 1980s. Informed by Jasanoff's conclusions about co-production (2004), Tunlid analyses the interplay between the development of knowledge and societal norms and values. The purpose is to show how medical knowledge of chromosomes, syndromes and disabilities was embedded in norms, values, and practitioners, and how the perception of foetal diagnosis was affected. This included everything from how healthcare practitioners should inform parents about foetal diagnosis to views on abortion. The medical knowledge and practical technology (foetal diagnostics) were interpreted differently in different social contexts. A dominant view in medicine is that cultural, social, and political values are barriers to be overcome; however, given co-production, Tunlid demonstrates that these values are integral to how biomedical technology, such as foetal diagnostics, is applied and regulated in society.

Regulation is also the topic of 'Evidence-informed policymaking 
at the World Health Organization', in which Rachel Irwin looks at how knowledge, evidence, and experience are used in the WHO's policymaking process. She compares two WHO recommendations - the UNICEF/WHO International Code of Marketing of Breastmilk Substitutes from 1981 and the Set of Recommendations on the Marketing of Foods and Non-alcoholic Beverages to Children from 2010-using interviews with key stakeholders, participant observation at the WHO's headquarters in Geneva, Switzerland, and archival material. As the UN's specialized agency for health, the process of drafting recommendations considers systematic reviews of scientific literature, recommendations set by expert committees, and data on disease trends and burdens. At the same time, the WHO is a political organization, and major policies must be agreed by all 194 member states who, in turn, are influenced by a range of private sector and civil society actors. Irwin examines how knowledge-in the form of evidence and experience-is used in the policy process, demonstrating with extended, historical case studies the changes in the type and quality of evidence used in policymaking, the different standards applied to determine what counts as knowledge, and the challenges of setting policy in the absence of evidence and experience.

In the second section-'Circulating and sharing medical knowledge' - the contributors' empirical base is modern biomedical settings, for example laboratories or communication professionals who translate the latest discoveries into press releases. Åsa Alftberg's chapter 'Sharing knowledge: Neuroscience and the circulation of knowledge', uses neuroscientists' reflections on how they share knowledge and findings, and especially the challenges, opportunities, and ethical dilemmas, to examine the knowledge circulation of cutting-edge neuroscience. A central topic is how scientific knowledge is sometimes seen as personal property that can be problematic to share with other researchers, but on other occasions sharing can be seen as something positive, with multiple career benefits for the individual researcher or for a research group. By examining the view that knowledge and knowledge circulation are the preserve of a privileged group — the creators of knowledge-Alftberg highlights 
the complexities of knowledge circulation. She also discusses how and why knowledge circulates, and what happens when knowledge ceases to be the exclusive property of a particular group and is used and transformed by other groups.

This perspective on circulation is further elaborated on by Karolina Lindh in the chapter 'Press releases as medical knowledge: Making news and identification in medical research communication'. Medical knowledge about the brain is not confined to labs, clinics, or the neuroscientific community. One way in which such knowledge leaves the labs and scientific communities and reaches the public is in the form of press releases. This chapter contributes with understandings about the negotiations that occur in the practices of writing these press releases. Press releases are understood here as a genre that facilitates social action. This implies that those involved in creating press releases must have a shared understanding of how press releases are written and read, and how the readers make sense of them. The chapter is based on interviews with communication professionals and neuroscience scholars working at two different Swedish universities. In this empirical material, Lindh examines the negotiations between different actors that occur as medical knowledge is transformed into press releases.

In the third section-'Co-creation of medical knowledge'action is considered to be something that is co-created. Markus Idvall examines informed consent procedures in clinical trials for Parkinson's disease treatment in 'The co-production of informed consent: How mutual trust is negotiated between scientists and participants in clinical trials'. Using ethnographic fieldwork at a university hospital, including observations, focus-group discussions, and interviews with doctors, nurses, patients with Parkinson's disease, and their carers, he looks at the knowledge process which the informed consent procedure triggers between scientists and participants. Drawing on Jasanoff (2004), he uses the concept of co-production to describe the process as informed trust, rather than informed consent. Specifically, he demonstrates how this process is not limited to the actual signing of an informed consent document, 
but rather how trust is negotiated-and renegotiated-between the patient and scientists before, during, and after the trials. These relations build on the interplay of the scientists' expert knowledge and the embodied experience of patients and their carers and their lay knowledge, as scientists and patients exchange sets of knowledge in the course of the trials. There are expectations on both sides. A 'good' research subject is a knowledgeable one, who takes responsibility; the responsibilities of the scientist include sharing information about the trial and the state of research on Parkinson's. However, the fragility of the consent process is undeniable.

Various processes of co-production and co-creation are also addressed in 'The co-creation of situated knowledge: Facilitating the implementation of care models in hospital-based home care' by Kristofer Hansson, Gabriella Nilsson, and Irén Tiberg. They argue that the evidence-based care models introduced into healthcare are a form of ontology that calls for specific ways of treating concepts such as healthcare, patient, treatment, and care. Such models aim to create a certain kind of explanation of a complicated reality where they are intended to work, but often there are so-called epistemological breaks, as a result of which the models are perceived incorrectly, create the opposite effect, or have unintentional consequences. These epistemological breaks are manifest during the implementation of new care models, when evidence-based medicine meets the older knowledge contained in the healthcare professionals' existing practices, habits, and performances. The chapter sets out an ethnographic method that can be used during such implementation processes to help bring together evidence-based care models and older knowledge as new care practices. The method focuses on how best to support the facilitator of the implementation of the group when they have to address any epistemological breaks that may arise; as the authors point out, knowledge is something that all involved must work on actively throughout the implementation process, truly creating situated knowledge together, and understanding that these different knowledges are the way forward.

The last section-'Knowledge in everyday experience'-continues 
with the healthcare context with Kristofer Hansson's chapter 'A Number in Circulation: $\mathrm{HbA} 1 \mathrm{c}$ as standardized practice in diabetes care'. $\mathrm{HbA} 1 \mathrm{c}$ is a blood value that measures how much sugar is bound to the red blood cells-haemoglobin $(\mathrm{Hb})$ - which, since the red blood cells are broken down after about 120 days and newly formed, can be used to assess the effectiveness of diabetes treatment. $\mathrm{HbA1c}$ readings are expressed in numbers, but these numbers are interpreted, translated, and understood in different ways depending on the context in which they are presented and used. In an ethnographic study, Hansson examines how the numbers are discussed in meetings both between health professionals and newly diagnosed children and their parents, and in working group meetings of health professionals. It is found that figures in medicine form normative guidelines, with numbers perceived as different types of knowledge depending on how they are used in practice. Specifically, the chapter considers the value 52 as a matter of knowledge-not just a figure that patients and families strive to achieve in the course of their treatment, but also a figure that generates a certain relationship between healthcare professionals and patients and their families. Similarly, it is also a figure that affects healthcare, with ramifications for quantification, measurement, and standardization in medicine.

The focus narrows to the purely individual in Max Liljefors's chapter 'Knowledge worlds apart: Aesthetic experience as an epistemological boundary object', which details a research project with an art exhibition for patients with Parkinson's disease, organized at an art gallery. Within the framework of the project, a new educational method was developed that focuses on aesthetic experience and bodily self-knowledge. This is in contrast to traditional art education, which primarily deals with art history and interpretation. In this way, Liljefors combines contemporary findings from the growing field of culture and health with older insights derived from aesthetic philosophy to argue that aesthetic experiences can constitute an essential aspect of the health dimension that is increasingly called 'existential' or 'spiritual' health. The chapter ends with an appendix where the current project method is described in detail with pedagogical texts and photographs. 
In the final chapter, Rui Liu and Susanne Lundin re-evaluate traditional models of the doctor-patient relationship in 'Medicines in the grey market: A sociocultural analysis of individual agency'. They draw on survey data and netnography to chart individuals' experiences buying medicines online. Liu and Lundin argue that deregulation of the retail pharmaceutical sector in Sweden opened the way to online sales of medicines, and while many sellers are legitimate pharmacies, consumers risk purchasing medicine of unknown providence from illegal or quasi-illegal sources. They find that the doctor-patient dialogue is not a hierarchical one, and that people take in multiple forms of knowledge, not only consulting their doctor, but also friends and even strangers online, and relying on their own experience. In a health system and society with neoliberal characteristics like Sweden, the individual is expected to take responsibility for self-care, and part of this involves gathering and synthesizing information, and making one's own treatment decisions.

Knowledge matters to all disciplines, including the medical humanities. Changes in biomedicine and healthcare require fresh knowledge perspectives, along with completely different ways of approaching the wider cultural and social context in which healthcare takes place. While we believe that the medical humanities have a given place in this co-construction of new knowledge, we also argue that the field needs to further develop its theories and methodologies. Our hope is that this volume will help the medical humanities to more fully address the movement of knowledge.

\section{References}

Beaulieu, Anne (2004), 'From brainbank to database: The informational turn in the study of the brain', Studies in History \& Philosophy of Science, C: Studies in History \& Philosophy of Biological \& Biomedical Sciences, 35(2), 367-90.

Becker, Carol S. (1992), Living and relating: An introduction to phenomenology (Newbury Park, CA: SAGE).

Bell, Daniel (1973/1999), The coming of post-industrial society: A venture in social forecasting (New York: Basic). 
Berner, Boel \& Corinna Kruse (2013) (eds.), Knowledge and evidence: Investigating technologies in practice (Linköping: Department of Thematic Studies, Technology \& Social Change, Linköping University).

Bohlin, Ingemar \& Morten Sager (2011) (eds.), Evidensens många ansikten: Evidensbaserad praktik i praktiken (Lund: Arkiv).

Buckland, Michael K. (2012), 'What kind of science can information science be', Journal of the American Society for Information Science \& Technology, 63(1), 1-7.

Carusi, Annamaria \& Aud Sissel Hoel (2014), 'Toward a new ontology of scientific vision', in Catelijne Coopmans, Janet Vertesi, Michael E. Lynch \& Steve Woolgar (eds.), Representation in scientific practice revisited (Cambridge: MIT Press).

Cole, Thomas R., Nathan S. Carlin \& Ronald A. Carson (2015), Medical humanities: An introduction (Cambridge: CUP).

Drucker, Peter Ferdinand (1969), The age of discontinuity: Guidelines to our changing society (London: Pan).

Dumit, Joseph (2004), Picturing personhood: Brain scans and diagnostic identity (Princeton: PUP).

Eklöf, Motzi \& Daniel Normark (2018), 'Den informatiska medicinen och ansvaret för den digitala patientens integritet', Socialmedicinsk tidskrift, 3, 345-55.

Engelbretsen, Eivind, Tony Joakim Sandset \& John Ødemark (2017), 'Expanding the knowledge translation metaphor', Health Research Policy \& Systems, 15(19).

Foucault, Michel (1980), Power/knowledge: Selected interviews and other writings 1972-1977 (New York: Pantheon).

Frans, Emma (2017), Larmrapporten (Stockholm: Volante).

Frykman, Jonas \& Nils Gilje (2003) (eds.), Being there: New perspectives on phenomenology and the analysis of culture (Lund: Nordic Academic Press).

Gottweis, Herbert (2008), 'Participation and the New Governance of Life', BioSocieties, $3(3), 265-86$.

Gutting, Gary (2005), Foucult: A very short introduction (Oxford: OUP).

Hacking, Ian (1996), 'The looping effects of human kinds', in Dan Sperber, David Premack \& Ann James Premack (eds.), Causal cognition: A multidisciplinary debate (Oxford: OUP).

Hansson, Kristofer \& Karolina Lindh (2018), 'The hamburgers in the fridge: An interview with Professor Nikolas Rose about interdisciplinary collaboration, neuroscience and critical friendship', Culture Unbound: Journal of Current Cultural Research, 10(1), 115-22.

Hansson, Kristofer (2017), 'A different kind of engagement: P. C. Jersild's novel A living soul', in Kristofer Hansson \& Markus Idvall (eds.), Interpreting the brain in society: Cultural reflections on neuroscientific practices (Lund: Arkiv förlag).

Hahn, Robert A. \& Gaines, Atwood D. (eds.) (1985), Physicians of Western medicine: Anthropological approaches to theory and practice (Dordrecht: Reidel).

Haraway, Donna Jeanne (1985/2000), 'A cyborg manifesto: Science, technology, and socialist-feminism in the late twentieth century', Posthumanism, 69-84.

Husserl, Edmund (1972 [1913]), Ideas: General introduction to pure phenomenology (New York: Collier).

Ihde, Don (2012), Experimental phenomenology: Multistabilities (New York: State University of New York Press).

Jasanoff, Sheila (2004), States of knowledge: The co-production of science and the social order (London: Routledge).

Jordan, Brigitte (1983), Birth in four cultures: [A crosscultural investigation of childbirth in Yucatan, Holland, Sweden and the United States]. 3. ed. (Montréal: Eden P.).Keating, 
Peter \& Alberto Cambrosio (2006), Biomedical platforms: Realigning the normal and the pathological in late twentieth-century medicine (Cambridge, MA: MIT).

King, Alexandra Clare, Peter Orpin, Jessica Woodroffe \& Kim Boyer (2017), 'Eating and ageing in rural Australia: Applying temporal perspectives from phenomenology to uncover meanings in older adults' experiences', Ageing \& Society, 37(4), 753-76.

Kleinman, Arthur (1988), The illness narratives: Suffering, healing, and the human condition (New York: Basic).

Kristeva, Julia, Marie Rose Moro, John Ødemark \& Eivind Engebretsen (2018), 'Cultural crossings of care: An appeal to the medical humanities', Medical Humanities, 44(1), 55-8.

Latour, Bruno (2003), 'Why has critique run out of steam? From matters of fact to matters of concern', Critical Inquiry [Special issue], 30(2), 25-248.

Latour, Bruno \& Woolgar, Steve (1979), Laboratory life: The social construction of scientific facts (Beverly Hills: Sage).

Lyotard, Jean-François (1979), La condition postmoderne: Rapport sur le savoir (Paris: Éditions de Minuit).

Mishler, Elliot G. (ed.) (1981), Social contexts of health, illness, and patient care (Cambridge: Cambridge U. P.).

Mol, Annemarie (2008), The logic of care: Health and the problem of patient choice (Abingdon: Routledge).

Nichter, Mark \& Lock, Margaret (eds.) (2002), New horizons in medical anthropology: Essays in honour of Charles Leslie (London: Routledge).

Nordgren, Lars \& Kristofer Hansson (2019), 'Introductions' (eds.), Health management: Vinst, värde, kvalitet $i$ hälso- och sjukvård (Stockholm: Sanoma utbildning).

Normark, Daniel (2019), 'Mobilising skill and making skill mobile: Crafoord's surgical tours in South America, 1950-1965', Lychnos, 127-149.

Östling, Johan, David Larsson Heidenblad \& Anna Nilsson Hammar (2020) (eds.), Forms of knowledge: Developing the history of knowledge (Lund: Nordic Academic Press).

Pellizzoni, Luigi (2001), 'The myth of the best argument: Power, deliberation and reason', British Journal of Sociology, 52(1), 59-86.

Pickstone, John V. (2000), Ways of knowing: A new history of science, technology and medicine (Manchester: MUP).

Roberts, Albert R. \& Yeager, Kenneth R. (eds.) (2006), Foundations of evidence-based social work practice (Oxford: Oxford University Press).

Rose, Nikolas (2007), The politics of life itself: Biomedicine, power, and subjectivity in the twenty-first century (Princeton: PUP).

Rose, Nikolas (2013), 'The human sciences in a biological age', Theory, Culture \& Society, 30(1).

Rosenberg, William \& Anna Donald (1995), 'Evidence based medicine: An approach to clinical problem-solving', $B M J$, 310, 1122-6.

Schütz, Alfred \& Talcott Parsons (1978), The theory of social action: The correspondence of Alfred Schutz and Talcott Parsons (Bloomington: Indiana University Press).

Secord, James A. (2004), 'Knowledge in transit', Isis, 94(4), 654-72.

Starr, Paul (1982), The social transformation of American medicine (New York: Basic Books).

Wiszmeg, Andréa (2017), 'Diffractions of the foetal cell suspension: Scientific knowledge and value in laboratory work', in Kristofer Hansson \& Markus Idvall (eds.), Interpreting the brain in society: Cultural reflections on neuroscientific practices (Lund: Arkiv).

Wynne, Brian (1996), 'Misunderstood misunderstanding: Social identities and public uptake of science', in Alan Irwin \& Brian Wynne (eds.), Misunderstanding science? The public reconstruction of science and technology (Cambridge: CUP). 